IN THE RED CROSS WORLD

\title{
SEMINAR IN DAKAR ON INFORMATION TECHNIQUES
}

The First Regional Seminar for Information and Public Relations Officers of Red Cross and Red Crescent Societies of French-speaking African countries was organized by the League of Red Cross Societies, in co-operation with the Senegalese Red Cross Society, in Dakar (Senegal) from 17 to 29 January 1977.

The aim of this seminar was to promote a better knowledge of information techniques among Societies of the Red Cross.

National Society Information and Public Relations Officers of thirteen countries took part in the seminar. Based on African experience in this field the seminar was centred on the promotion of Red Cross knowledge among rural populations, as well as on learning professional techniques in the fields of press, radio, television, and methods of communicating with the public. Radio, one of the most effective means of sensitizing rural African populations, was a major item on the seminar's programme.

\section{EUROPEAN SEMINAR ON DISSEMINATION OF KNOWLEDGE OF GENEVA CONVENTIONS}

The first European Red Cross seminar on dissemination of knowledge of the Geneva Conventions took place in Warsaw from 21 to 29 March ${ }^{1}$. It was attended by about eighty delegates from twenty-three National Red Cross Societies of Europe and North America, and by representatives of the International Committee of the Red Cross and the League of Red Cross Societies.

Under the patronage of the Polish Premier, Henryk Jablonski, the seminar was organized jointly by the Polish Red Cross and the ICRC. Its purpose was to enable National Societies to exchange their views and experiences in order to improve the dissemination of knowledge

\footnotetext{
${ }^{1}$ Plate.
} 